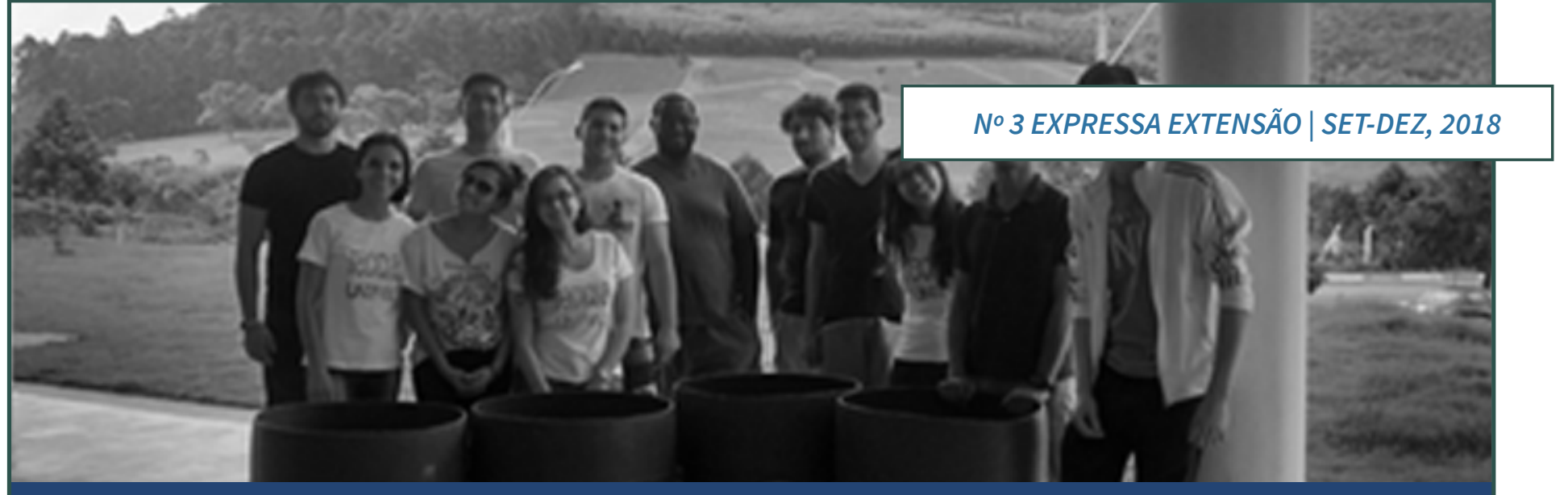

\title{
RECICLA UNIFAL-MG: PROJETO DE AÇÃO CONTÍNUADA PARA A PROMOÇÃO DA COLETA SELETIVA NO ESPAÇO ACADÊMICO
}

RECICLA UNIFAL-MG: CONTINUED ACTION PROJECT FOR THE PROMOTION OF SELECTIVE COLLECTION IN THE ACADEMIC SPACE

Luiz Felipe Ramos Turci ${ }^{1} \quad$ Giselle Patrícia Sancinetti ${ }^{2}$ Laura Luiza Oliveira dos Santos ${ }^{3}$ Letícia Ferreira Galvão Amaral Silveira ${ }^{4}$ Tábata de Oliveira ${ }^{5}$ Matheus Mendonça Ramos Simões ${ }^{6}$

\section{RESUMO}

O Recicla Unifal promove ações de implementação e fortalecimento da coleta seletiva na Universidade Federal de Alfenas-MG, campus Poços de Caldas e também no município. As ações têm o objetivo de conscientizar tanto o núcleo acadêmico quanto a população da cidade à realização da coleta seletiva. Para isso, o projeto mantém apublicação contínua de material digital via endereço eletrônico, rede sociale mala direta; realiza palestras no campus e em escolas municipais, participa de campanhas de mobilização social, etc.Além das atividades de educação e conscientização de caráter contínuo, dentre as atividades realizadas, o Recicla Unifal mantém a participação na coleta seletiva de festasuniversitárias; mantém ações de estímulo à coleta seletiva em moradias estudantis; realiza campanha deeconomia de energia na universidade. Dentre suas ações, destaca-se o projeto piloto de implantação de Pontos de Entrega Voluntário (PEV) em bairros do município, realizando o projeto e montagem do PEV, campanhas, monitoramento e análise dos resultados. Desde a implantação do Recicla Unifal, a coleta de materiais tem crescido e ogrupo tem conquistado seu espaço entre a comunidade acadêmica e Poços-caldense.

Palavras-chave: Educação ambiental. Gestão de resíduos sólidos. Coleta seletiva. Reciclagem.

\footnotetext{
${ }^{1}$ Universidade Federal de Alfenas - Brasil - Professor Doutor em Engenharia Eletrônica e Computação - felipeturci@gmail.com; ²Universidade Federal de Alfenas - Brasil - Professora Doutora em Engenharia Química - giselle. sancinetti@unifal-mg.edu.br; ${ }^{3}$ Universidade de São Paulo - Brasil - Mestranda pelo Programa de Pós-graduação em Sustentabilidade, Pós-graduanda MBA em Gestão Ambiental e Desenvolvimento Sustentável, e Graduada em Engenharia Química - lauraluizaos@gmail.com; ‘Pontifícia Universidade Católica de Minas Gerais - Brasil - Bolsista do programa FIP - Idaubian@gmail.com; ${ }^{5}$ Centro Estadual de Educação Tecnológica Paula Souza - Brasil - Possui graduação em Engenharia Química e graduação Interdisciplinar em Ciência e Tecnologia - tabata_oliveira09@yahoo.com.br; ‘Universidade Federal de Alfenas - Brasil - Engenheiro de Minas - mateusmrsimoes@ hotmail.com
} 


\section{ABSTRACT}

Recicla Unifal promotes actions of implementation and strengthening of the selective collection at the Federal University of Alfenas-MG, Poços de Caldas campus, and also in the municipality. The actions aim to make the academicnucleus and the population of the city a ware of the selective collection. For this purpose, the project maintains the continuous publication of digital material via electronicaddress, social network anddirect mail; conducts lectureson campus and in municipal schools, participates in social mobilization campaigns, etc. In additiontocontinuingeducationandawarenessactivities, amongtheactivitiescarried out, ReciclaUnifalmaintains its participation in theselectivecollectionofuniversityfestivities; maintainsactionstostimulatetheselectivecollection in studenthousing; carries out an energy saving campaign at the university. Among its actions, wehighlight the pilot project of implementatio nof Voluntary Delivery Points (VDP) in neighborhoods of the municipality, carrying out the design and assembly of the VDP, campaigns, monitoringandanalysisofresults. Since the implementation of ReciclaUnifal, the collection of materials has grown and the grouph as conquered its space between the academic and Poços de Caldas community.

Keywords: Environmental education. Solidwaste management. Selective collection. Recycling.

\section{INTRODUÇÃO}

Atualmente, um dos graves problemas que a sociedade enfrenta é a questão da poluição ambiental. O crescimento industrial e o aumento da população urbana acarretaram no aumento da produção de bens de consumo, e como consequência, maior produção de resíduos, os quais normalmente não possuem o destino correto e acabam poluindo o meio ambiente. Essa poluição ocorre principalmente pela falta de consciência da população em relação à educação ambiental, bem como a falta de incentivo à coleta seletiva nas comunidades, a não reutilização dos produtos para outros fins, além de outras práticas que diminuiriam os resíduos gerados.

Tendo em vista a problemática da disposição inadequada do resíduo no meio ambiente, a coleta seletiva mostra-se interessante, uma vez que ela agrega três pontos importantes, tais como, reduzir o resíduo ao máximo, reaproveitar tudo que for possível e por fim destinar os materiais à reciclagem. Uma sociedade consciente e bem educada não gera lixo e sim materiais para reciclar, de forma a contribuir com a economia mundial, cuidando do meio ambiente, diminuindo a poluição e evitando problemas ambientais graves.

No Brasil, cerca de 65,3\% das embalagens pós-consumo são efetivamente recicladas, apesar disso, apenas $14 \%$ dos municípios brasileiros oferecem serviço de coleta seletiva. Este fato vem alarmando a sociedade ambientalista, uma vez 
que o plástico, por exemplo, pode demorar até 100 anos para se decompor, o que acarreta em grandes depósitos de garrafas (além de outros resíduos) em leitos de rios, lixões, entre outros, podendo provocar problemas e desastres ambientais (CEMPRE, 2013).

Apesar da ineficiência do Estado, com a escassez de emprego, muitas pessoas buscaram fontes alternativas de renda, como a coleta e revenda de materiais reciclados. Os catadores, como são conhecidos, retiram do lixo materiais que possuem características de reuso ou reciclagem. Os materiais recicláveis são recuperados, principalmente, através de catadores e cooperativas, além de fábricas e da coleta seletiva operada por municípios (CEMPRE, 2013).

A coleta seletiva na UNIFAL-MG, campus de Poços de Caldas, foi implementada através da primeira edição 2014/2015 do projeto Recicla Unifal, intitulado "Proposta de Implantação de Coleta Seletiva no Campus de Poços de Caldas da UNIFAL-MG"; projeto premiado no $1^{\circ}$ Simpósio Integrado da UNIFAL-MG. Durante a primeira edição do projeto criou-se a marca Recicla Unifalutilizada como título do projeto. Desde então, as ações do projeto visam conscientizar tanto o núcleo acadêmico quanto a população da cidade à realização da coleta seletiva. $O$ projeto mantém apublicação contínua de material digital via endereço eletrônico (http://reciclaunifal.wixsite.com/sustentabilidade), rede social (https://www. facebook.com/recicla.unifal) e mala direta (recicla.unifal@gmail.com); realiza palestras no campus e em escolas municipais, participa de campanhas de mobilização social, etc. Além das atividades de educação e conscientização, o Recicla Unifal mantém a participação na coleta seletiva de festasuniversitárias; mantém ações de estímulo à coleta seletiva em moradias estudantis; realiza campanha deeconomia de energia na universidade. Dentre suas ações, destaca-se o projeto piloto de implantação de Pontos de Entrega Voluntário (PEV) em bairros do município, realizando o projeto e montagem do PEV, campanhas, monitoramento e análise dos resultados.

Este artigo traz uma breve revisão bibliográfica no contexto da coleta seletiva no qual o Recicla Unifal está inserido e, principalmente, faz um relato das ações de promoção da coleta seletiva tanto no espaço acadêmico quanto no município de Poços de Caldas.

\section{FUNDAMENTAÇÃO TEÓRICA}

\section{Resíduos sólidos urbanos}

O alto índice de crescimento populacional das últimas décadas vem acentuando e exigindo grande demanda de matéria prima, produtos e bens de consumo, acarretando em maior número de dejetos e resíduos tanto na fabricação quanto após o uso. 
Esses resíduos, entretanto, em sua grande parte, não possuem destino apropriado e a maior parte dos Resíduos Sólidos Urbanos (RSU) são armazenados nos aterros sanitários, sendo que boa parte desses aterros não possui infraestrutura adequada para recebê-los. Isso causaimpactos à sociedade e ao meio ambiente, ocasionando acentuado problema ambiental como a poluição da água e do solo (MARCHEZETTI, 2009).

De forma global, os países desenvolvidos foram os pioneiros na busca por uma alternativa para tratamento e a diminuição dos RSU nos aterros. Medidas como o Reaproveitamento e a Reciclagem são grandes aliadas no combate aos "lixões", entretanto ainda não são medidas tão eficazes, restando assim alternativas como a incineração, a gaseificação, a compostagem, e a redução por plasma, que visam à produção de resíduos menos danosos ao meio ambiente.

No Brasil, foi possível reformular o sistema de gerenciamento de resíduos sólidos através de audiências públicas, com apoio acadêmico e de representantes municipais, desenvolvendo uma nova Política Nacional de Resíduos Sólidos, aprovada em 2010, que estabeleceu regras gerais, direcionando o país para um gerenciamento de resíduos eficiente. Uma das principais metas que constam nesta Política é o fato de colocar 2014 como prazo final para o uso dos lixões (CEMPRE, 2012).

Segundo a Pesquisa Nacional de Saneamento Básico (IBGE, 2008), os primeiros programas de coleta seletiva e reciclagem dos resíduos sólidos no Brasil começaram a partir de meados da década de 1980, como alternativas para a redução da geração dos resíduos sólidos domésticos e estímulo à reciclagem.

Desde então, comunidades organizadas, indústrias, empresas e governos locais têm sido mobilizados e induzidos à separação e classificação dos resíduos nas suas fontes produtoras. Tais iniciativas representaram um grande avanço no que diz respeito aos resíduos sólidos e sua produção.

\section{Coleta seletiva}

A coleta seletiva é um sistema que recolhe materiais recicláveis como, papéis, plásticos, vidros, metais e orgânicos, rapidamente separados na fonte geradora e que podem ser reciclados ou reutilizados. Contribui na melhoria do meio ambiente, na medida em que diminui a exploração de recursos naturais, reduz o consumo de energia, diminui a poluição do solo, da água e do ar, prolonga a vida útil dos aterros sanitários, diminui os gastos com a limpeza urbana, possibilita a reciclagem de materiais que iriam para o lixo, cria oportunidade de fortalecer organizações comunitárias e gera emprego e renda pela comercialização dos recicláveis (CEMPRE, 2014). 
Em âmbito nacional a principal Lei é a Política Nacional de Resíduos Sólidos, Lei $n^{\circ}$ 12.305, 2010 (BRASIL, 2010), que foi sancionada no dia 2 de agosto de 2010 após ter ficado em tramitação no Congresso Nacional por vinte e um anos (REDAÇÃO ECOD, 2011). Outro documento existente no âmbito nacional é o decreto federal $N^{\circ}$ 5.940, de 25 de outubro de 2006 (BRASIL, 2006). Dentre os artigos presentes no decreto, o primeiro informa de modo claro que as entidades públicas federais estão obrigadas a elaborar um plano de resíduos, fazer a separação dos materiais recicláveis e enviá-los exclusivamente para cooperativas. Em âmbito estadual, existe a política dos resíduos sólidos do Estado de Minas Gerais, $n^{\circ} 18719$ de 13 de janeiro de 2010 (MINAS GERAIS, 2010). Junto com a Lei n. 8.316 de Poços de Caldas, estas normas regulamentam localmente a gestão de resíduos sólidos (POÇOS DE CALDAS, 2006).

Com relação à coleta seletiva de materiais recicláveis, entre 2000 e 2008 houve aumento de $120 \%$ no número de municípios que desenvolveram tais programas, e chegaram a 994, estando a maioria localizada nas regiões Sul e Sudeste. Esse marco, embora importante, ainda não ultrapassa $18 \%$ dos municípios brasileiros (BRASIL, 2010). Em 2010, dos 5.565 municípios existentes no Brasil (IBGE, 2011), 3.205 (57,6\%) indicaram a existência de iniciativas de coleta seletiva. Embora a quantidade de municípios com atividades de coleta seletiva seja expressiva, é importante considerar que muitas vezes tais atividades se resumem na disponibilização de pontos de entrega voluntária à população ou na simples formalização de convênios com cooperativas de catadores para a execução dos serviços (ABRELPE, 2010).

Segundo os dados do IBGE (2015)o Brasil apresenta 5.570 municípios. No entanto de acordo com o CEMPRE (2015) somente 927 destes municípios utilizam programas de coleta seletiva, porém a maior parte deles não cobre mais que $13 \%$ da população local.

As coletas seletivas municipais seguem os sistemas operacionais porta a porta e entrega voluntária. Em torno de $80 \%$ dos municípios realizam coleta seletiva de porta a porta, onde o caminhão passa nos domicílios em determinados dias da semana para recolher os materiais recicláveis. Já $45 \%$ dos municípios utilizam postos de entrega voluntaria (PEV) como alternativa para a população participar da coleta seletiva. Além desses sistemas, $76 \%$ dos municípios utilizam as cooperativas de catadores que também executam um papel importante no ciclo de reciclagem - dados CEMPRE (2015).

Os programas municipais de coleta seletiva permanecem concentrados nas regiões Sudeste e Sul do país, com $81 \%$ do total de municípios brasileiros que possuem esse serviço. O custo da coleta seletiva é quatro vezes maior que o custo de uma coleta convencional. Nas grandes cidades estima-se um custo médio de $\mathrm{R} \$ 367,20$ por tonelada (CEMPRE, 2010). 


\section{O município de Poços de Calda}

De acordo com o contabilista e autor da obra Manual das Cooperativas (ZANLUCA, 2012), cooperativa é uma associação de pessoas com interesses comuns, economicamente organizadas de forma democrática, isto é, contan $\neg$ do com a participação livre de todos e respeitando direitos e deveres de cada um de seus cooperados, aos quais presta serviços, sem fins lucrativos.

De acordo com a Cooperativa Ação Reciclar, atuante nomunicípio de Poços de Caldas, esta recebe cerca de oitenta e cinco toneladas por mês em materiais, sendo que deste total aproximadamente $10 \%$ é composto por lixo não reciclável ou reaproveitável. Tal fato ocorre devido à falta de conscientização da população ou até mesmo pela falta de conhecimento sobre a coleta seletiva no município. É possível que com a divulgação e com programa de uma coleta seletiva adequada essa realidade mude no município, visto que a Cooperativa tem capacidade para recolher cento e quarenta toneladas por mês de materiais.

Até 2016, a Cooperativa atendia cerca de $40 \%$ da cidade, esta cobertura ainda é pequena, tendo em vista o grande potencial que a cidade de Poços de Caldas possui, devido a problemas econômicos, como por exemplo, a falta de transporte para coleta seletiva ou até mesmo logística adequada da coleta destes materiais. A partir de 2017, a prefeitura assumiu o compromisso de realizar a coleta seletiva porta a porta em todos os bairros do município, destinando a coleta às cooperativas Ação Reciclar e Coopersul.

\section{Implantação de coleta seletiva}

De acordo com Souza et al. (2014), o estudo da logística e da destinação dos resíduos faz parte do processo de implantação da coleta seletiva que está divido em três elos, sendo o primeiro a destinação, o segundo a logística a ser utilizada e o terceiro a educação ambiental. Porém sobre o processo de implantação ainda pode-se observar que alguns autores colocam o estudo da logística e local de depósito dos resíduos em primeiro plano e, após isso, a parte da sensibilização.

De forma ainda mais completa, Bringhenti (2004)aponta uma sequência de cinco etapas: (i) um estudo prévio do perfil sociocultural e dos resíduos produzidos, (ii) o planejamento da estratégia de educação e a análise dos custos operacionais do sistema, (iii) a implementação dos pontos de coleta, (iv) o acompanhamento do desenvolvimento do projeto por meio da análise dos dados referentes ao peso e volume de materiais coletados e, por fim, (v) a análise dos benefícios atuais da implantação da coleta. 


\section{Caracterização}

Uma das etapas principais antes da implantação da coleta seletiva é o processo de caracterização dos resíduos sólidos produzidos pela comunidade do local estudado. Tal caracterização consiste em determinar a composição dos resíduos gerados em um lugar, de modo que, ao final obtém-se a identificação dos resíduos nos diversos tipos, e as respectivas quantidades dos resíduos separados (BASSANI, 2011). Tal exercício de caracterização é fundamental para a implantação da coleta seletiva, pois é possível analisar a porcentagem do resíduo que pode ser reciclada e verificar o resultado financeiro, ajudando também no planejamento da administração do projeto, como exemplo, qual será o tipo de local para armazenamento dos resíduos separados, qual será o intervalo do recolhimento dos resíduos, entre outros.

Para a realização da caracterização, podem-se analisar os resíduos em foco de forma censitária (todos os resíduos) ou de forma amostral. Para tal decisão, é importante considerar a quantidade da geração de resíduos, pois caso o montante de resíduo gerado for muito grande, torna-se inviável analisar de forma censitária, de mesma forma que é inconsistente fazer uma coleta de amostra de um pequeno montante de resíduos.

Segundo Fuzaro e Ribeiro (2005)e Frésca (2007)as amostras coletadas devem ser despejadas em um local protegido com uma manta plástica ou pavimentado, e então homogeneizar os resíduos com a ajuda de ferramentas adequadas como garfos e rastelos. É importante, também, que os resíduos sejam separados e pesados em no máximo dois dias, evitando a grande exposição e a alterações físicas e químicas do material (EUROPEAN COMMISSION, 2004 apud BASSANI, 2011).

\section{Logística}

Projetos pilotos de reestruturação da coleta seletiva com o uso de PEV mostram bons resultados (RIBEIRO; LIMA, 2000). Mesmo em casos em que não se tem obtido aumento significativo na quantidade de material, exemplo de Santo André (CRUSEIRO, 2008), o rejeito, antes da ordem de $70 \%$, caiu para $30 \%$ em média.

\section{Resíduos no campus de Pocos de Caldas}

Souza et al. (2014) desenvolveram trabalho que possibilitou a caracterização dos resíduos gerados no campus. Foi feita quantificação dos resíduos sólidos e obtidas as principais características, como a composição gravimétrica e o peso aparente do resíduo gerado. Constataram que o resíduo orgânico era a 
maior parcela gerada no campus, com $72,1 \%$, seguido de resíduo não reciclável, $20,2 \%$, e de resíduo reciclável, $8,3 \%$. Este último representou aproximadamente $5,7 \mathrm{~kg} / \mathrm{dia}$.

Um grande problema ainda enfrentado no campus de Poços de Caldas é a falta de locais apropriados para a destinação dos resíduos sólidos, tanto o armazenamento do material reciclável, quanto o descarte do lixo. Na figura 1, pode-se ver o local de destinação dos resíduos - observa-se a inadequação do local, com materiais recicláveis expostos ao tempo, em contato com o lixo que se espalha no entorno da gaiola. Nesse contexto se insere o projeto Recicla Unifal, projeto que atua na seleção de material, o logística e a educação ambiental no campus de Poços de Caldas da UNIFAL-MG.

Figura 1 - Depósito de resíduos sólidos no campus de Poços de Caldas.

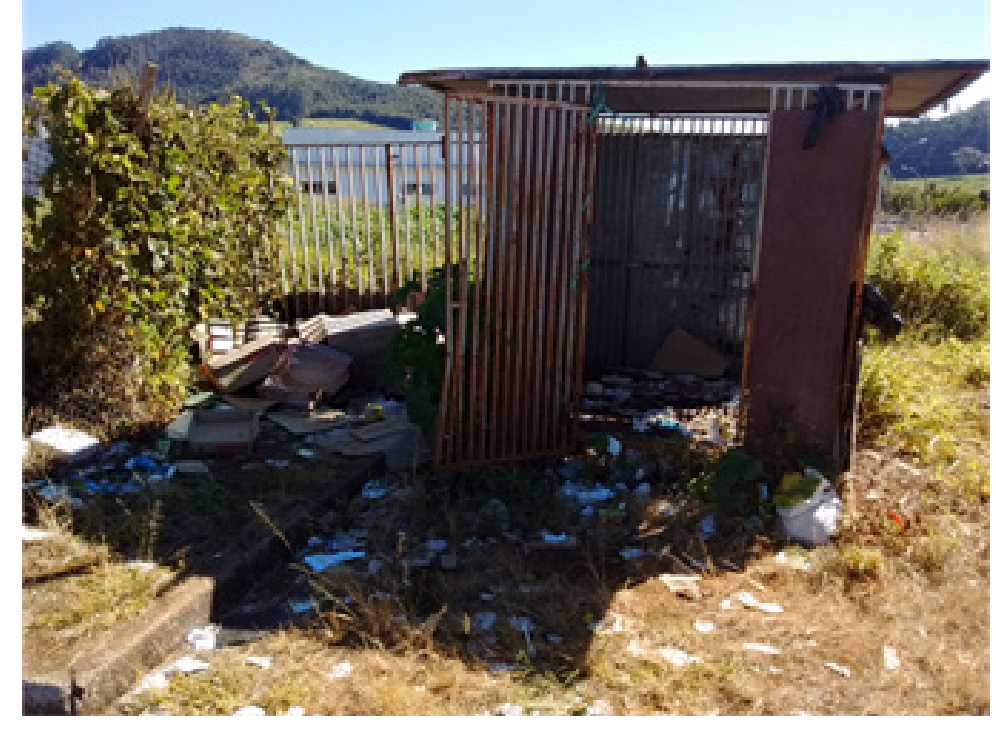

Fonte: Fotografia dos autores

\section{OBJETIVOS}

O objetivo geral do Recicla Unifal é a contribuição para a manutenção e ampliação da coleta seletiva no campus de Poços de Caldas da UNIFAL-MG e no município de Poços de Caldas. A fim de cumprir esse objetivo, objetivos específicos precisam ser atingidos:realização de campanhas educativas para sensibilização da comunidade do campus a respeito da necessidade e do correto procedimento de descarte seletivo; realização de campanhas educativas e estruturação das escolas municipais para a prática da coleta seletiva;realização e participação em eventos de mobilização social; ampliação, com apoio institucional, a infraestrutura de coleta seletiva no campus;projeto piloto de implantação de PEV em bairros do município de Poços de Caldas. 


\section{MÉTODOS}

O campusPoços de Caldas da UNIFAL-MG possui características multidisciplinares, uma vez que os cursos nos quais os discentes estão matriculados (Bacharelado Interdisciplinar em Ciência e Tecnologia ou Engenharias Ambiental, Minas e Química) permitem aos mesmos a possibilidade do desenvolvimento de novas tecnologias, contribuindo assim para melhoria do meio em que vivem. Assim, o grupo destinado à execução deste projeto é interdisciplinar e conta com profissionais qualificados, sendo dois professores, um técnico, e diversos alunos que já passaram pelo projeto ao longo dos anos. A metodologia do projeto baseia-se na Pesquisa-Ação, em que todas as atividades são propostas e discutidas em encontros semanais. A implementação da coleta seletiva no campus seguiu as etapas de caracterização (executada por um grupo de alunos não vinculados ao Recicla Unifal, mas orientados por um docente membro deste), implementação da logística e destinação do material reciclável coletado. Como as principais ações do projeto caracterizam-se como ações de educação ambiental, estas demandam intensivo trabalho de revisão bibliográfica, design gráfico, e webdesign. O material de educação ambiental produzido é utilizado em campanhas eletrônicas, palestras e eventos. No que tangem ações voltadas à implementação e aprimoramento de infraestrutura necessária para coleta seletiva municipal, algumas ações apresentam metodologias muito específicas, que serão apresentadas nas seções que tratam do tema.

\section{RESULTADOS}

\section{Coleta seletiva no campus de Poços de Caldas}

O primeiro passo para a implantação da coleta seletiva no campus de Poços de Caldas da UNIFAL-MG foi o estabelecimento de um convênio entre a universidade e a cooperativa de catadores Ação Reciclar que seria a responsável pela retirada e apropriada destinação do material reciclável coletado no campus. Esse convênio garante a correta destinação do material do ponto de vista ambiental, além de ter significativa importância social, uma vez que contribui com a geração de renda dos cooperados.

Com relação à infraestrutura, as lixeiras do campus foram adesivadas, identificando aquelas destinadas à coleta de material reciclável e não reciclável (Fig.2); lixeiras que também tiveram seu número aumentado em trinta e quatro unidades devido à doação feita pela empresa M\&G Fibras Brasil de vinte tambores de 20L (Fig.3) e catorze coletores para papel A4 (Fig.4). Os coletores de papel foram colocados principalmente nas áreas administrativas, prédio de gabinetes de docentes, laboratórios, papelaria e biblioteca. Além das lixeiras, um PEV (Ecoponto doado pelo Projeto Novo Ciclo) foi colocado no prédio de salas de aula; assim, todo o material coletado nas lixeiras pode ser depositado no PEV. Assim, estabelecemos a logística de coleta e destinação no campus. 
A equipe do projeto realiza a divulgação contínua da coleta seletiva em todas as salas de aula e entre os servidores e terceirizados. Foi criado um site como forma de divulgação de notícias sobre a reciclagem, monitoramento e demais ações envolvendo coleta seletiva: http://reciclaunifal.wix.com/sustentabilidade. O trabalho de educação para a coleta seletiva conta com monitoramento da retirada dos recicláveis pelo caminhão da cooperativa Ação Reciclar (Fig.5). Semanalmente são feitos acompanhamentos das lixeiras do campus(Fig.6), as fotos são tiradas de segunda à sexta e colocadas no Facebook (Sustentabilidade Unifal) para divulgação e motivação para a continuação da separação dos recicláveis; a cada semana um ponto de coleta é monitorado de forma a abranger todo o campus.

Adotamos também o envio de mala direta semanal por email para que, principalmente servidores que não acessam mídias sociais, pudessem ser informados sobre a coleta, e também com textos orientadores sobre a separação de material, reportagens, notícias sobre coleta seletiva, materiais recicláveis, dentre outros (Fig.7).

Figura 2 - Identificação das lixeiras do campus de Poços de Caldas.

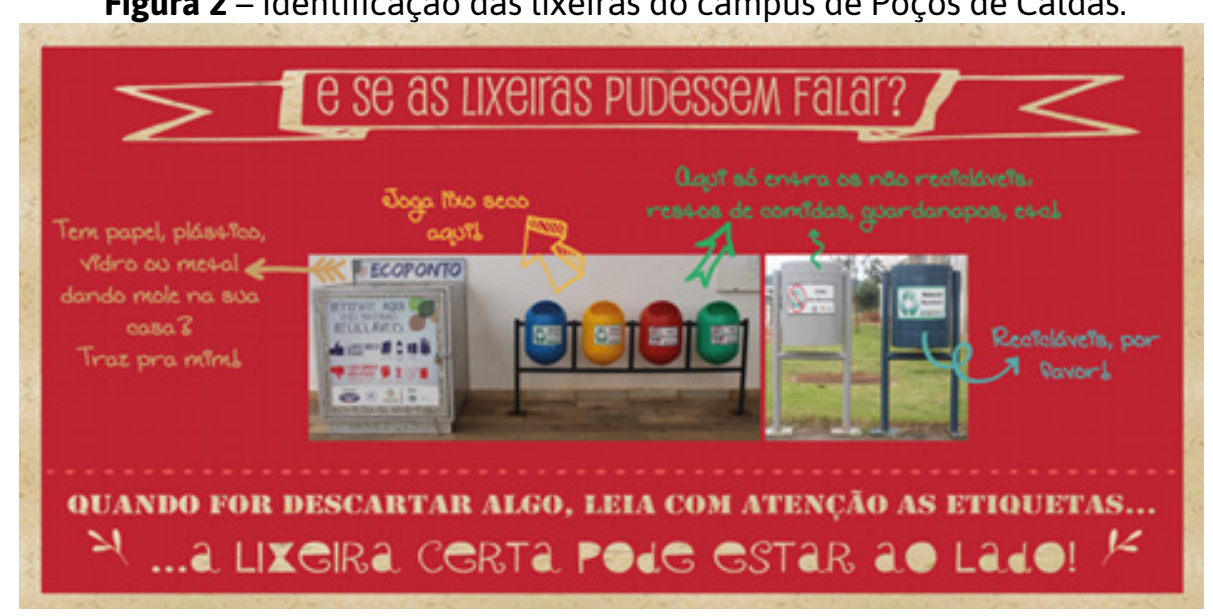

Fonte: autores 
Figura 3 - Lixeira de tambor.

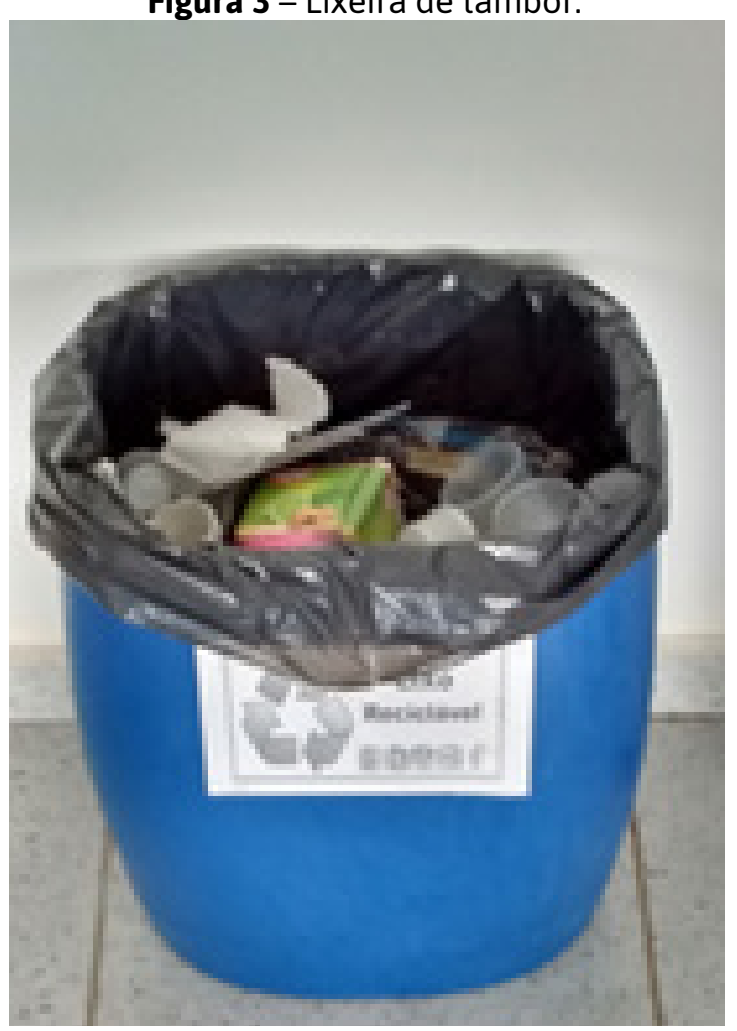

Fonte: autores

Figura 4 - Coletores de papel

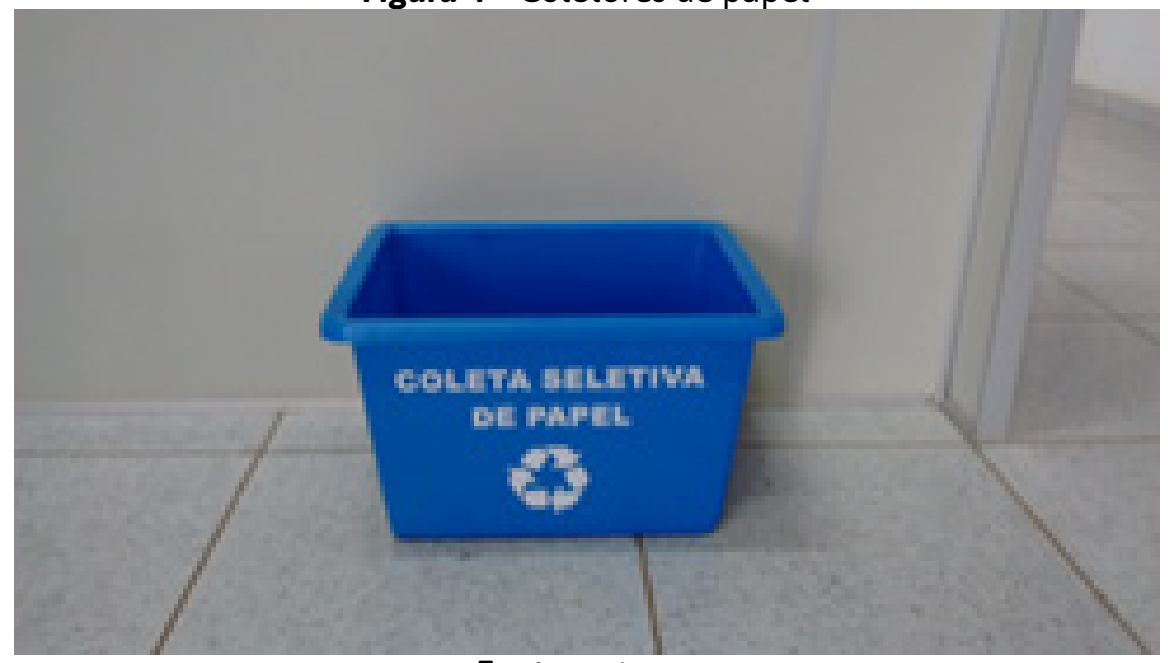

Fonte: autores 
Figura 5 - Monitoramento do PEV.

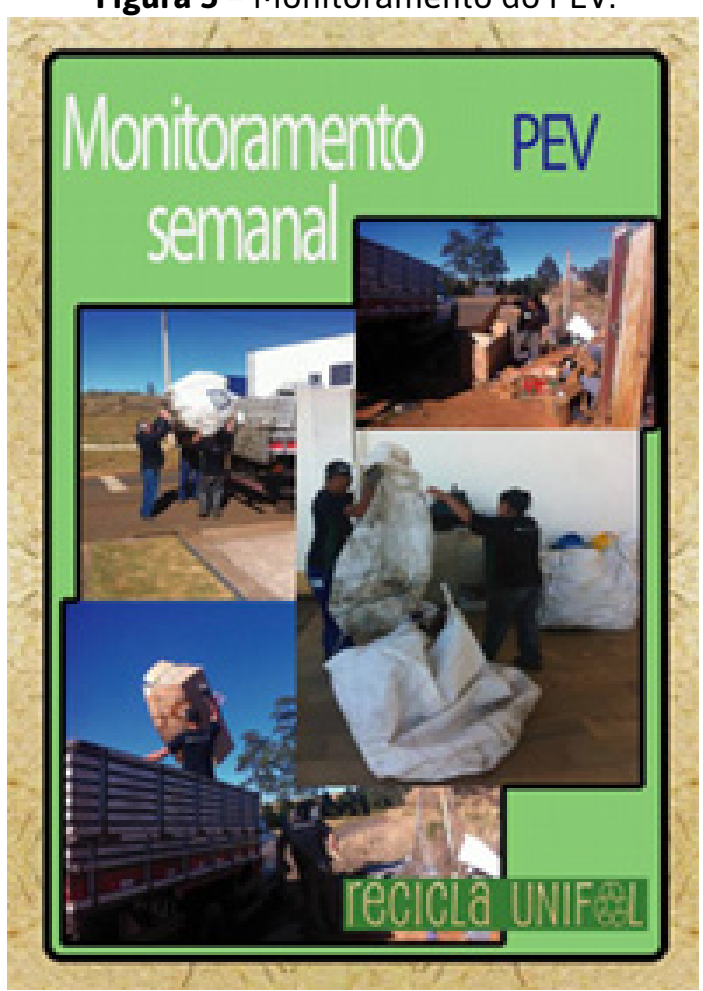

Fonte: autores

Figura 6 - Monitoramento de lixeiras

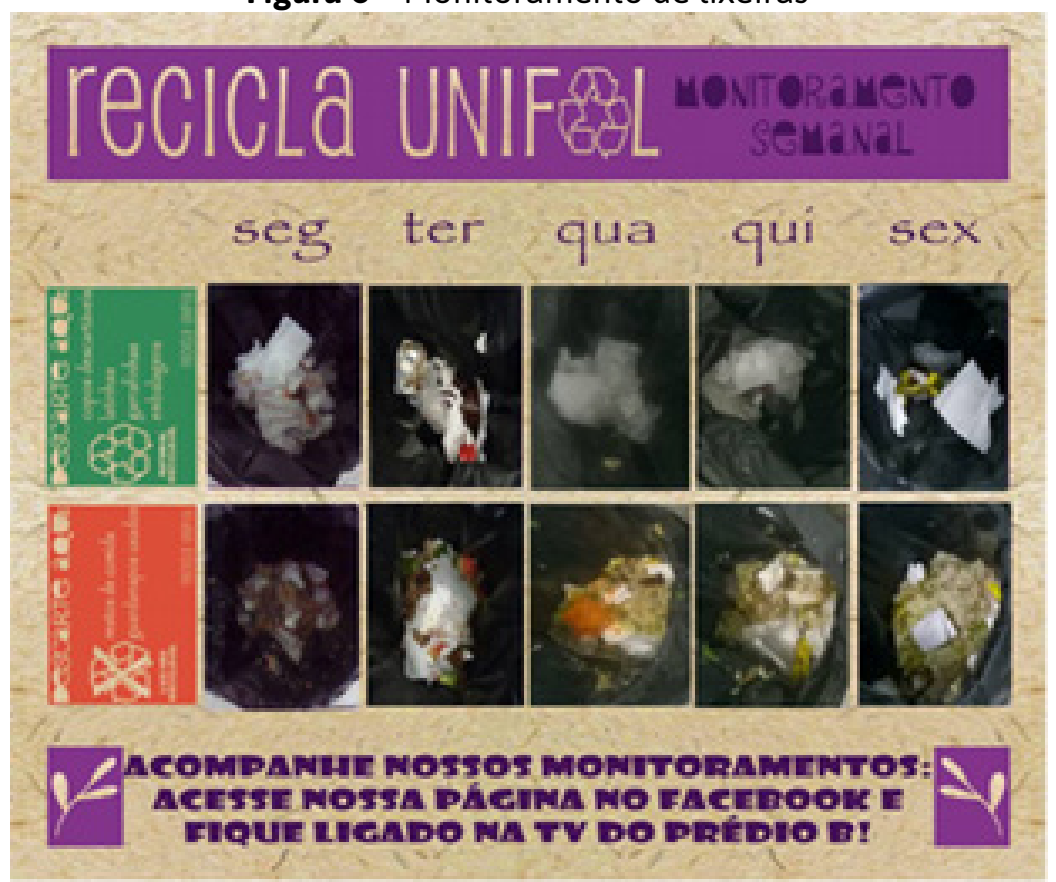

Fonte: autores 
Figura 7 - Exemplo de mala direta.

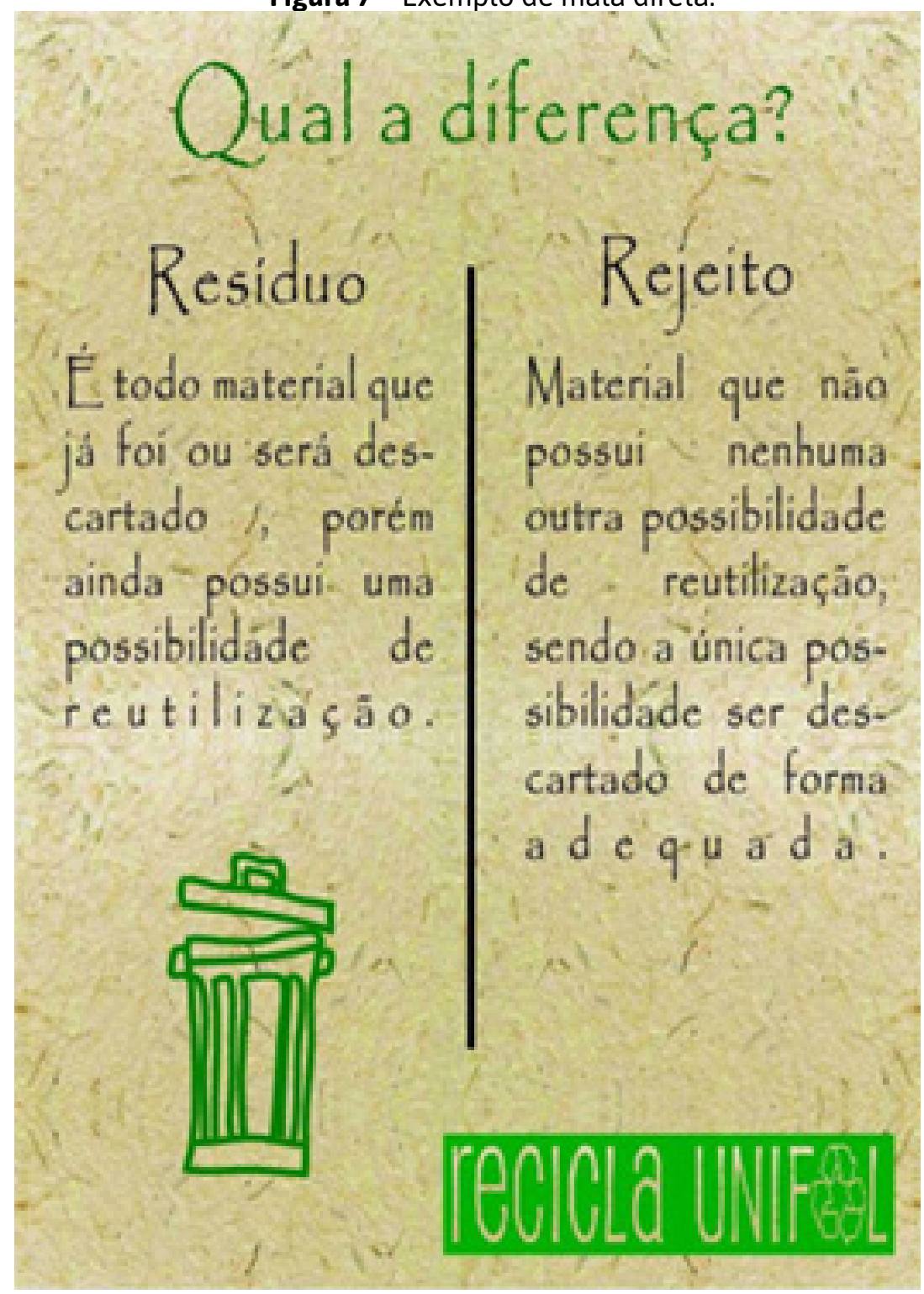

Fonte: autores

Em 2016 iniciamos a campanha de coleta de óleo usado para reciclagem e disponibilizou-se um ponto de coleta de óleo no campus (Fig.8). Todo óleo coletado é recolhido pela cooperativa Coopergore. 
Figura 8 - Coleta de óleo

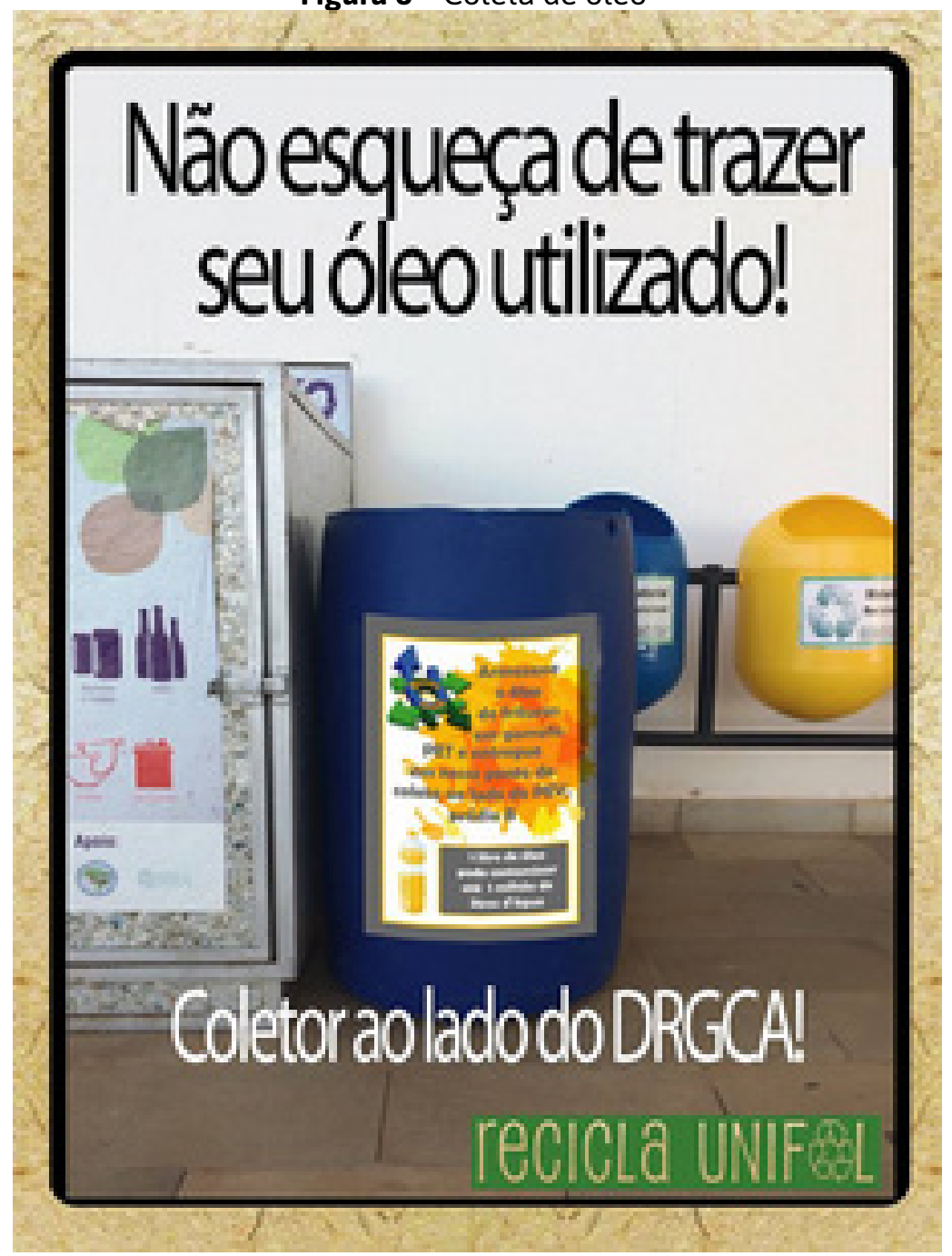

Fonte: autores.

Além da doação dos tambores de 50L, conseguiu-se também 10 tambores de $200 \mathrm{~L}$ com a empresa M\&G Fibras Brasil. Foi lançada uma campanha de cadastramento das repúblicas que quisessem receber o tambor de 200L para coleta dos recicláveis e encaminhamento à cooperativa. Os tambores foram identificados com adesivos: República Amiga do Recicla. Oito repúblicas receberam os tambores, e assumiram o compromisso de registrar com fotos a coleta e retirada dos recicláveis pela cooperativa (Fig.9). 
Figura 9 - República Amiga Recicla UNIFAL.

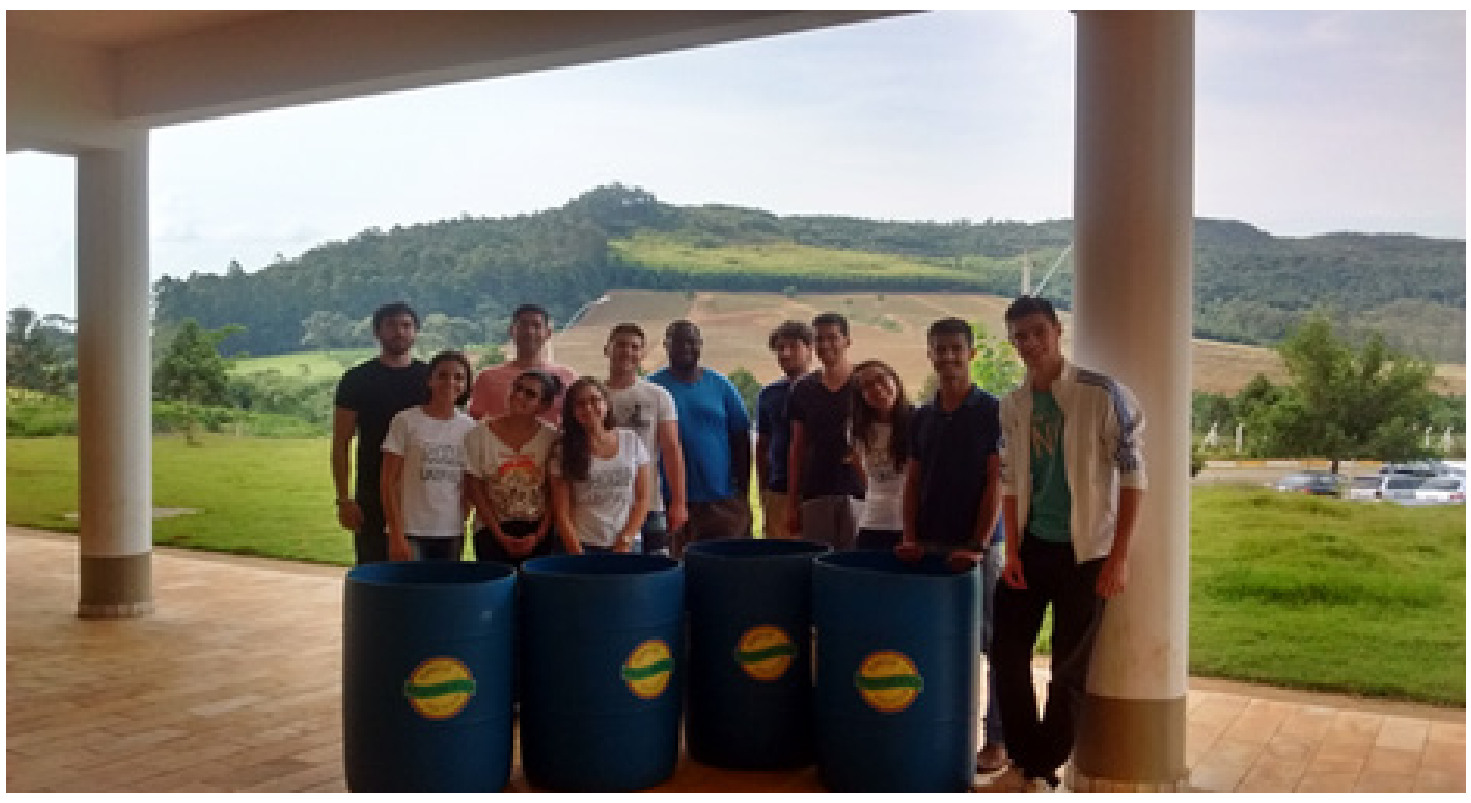

Fonte: autores

\section{Ações externas}

Além dos resultados apresentados, projeto realiza uma série de outras atividades que reforçam a justificativa de sua continuidade. Uma das bolsistas passou a frequentar as reuniões da Associação Poços Sustentável (APS) e com isso surgiu a oportunidade da equipe participar do Giro Sustentável 2015: Água eu utilizo, eu preservo. Nesse evento, outras instituições de ensino, indústrias, prefeitura e cooperativa Ação Reciclar participaram da organização. A equipe do Recicla UNIFAL ficou encarregada ajudar na divulgação da cooperativa no município. Com isso organizou a exposição de fotos: "Para onde vai seu Reciclável". Esta exposição ocorreu entre os dias 19 a 27 de setembro no shopping Poços de Caldas (Fig.10) com participação de membros do Recicla UNIFAL e da cooperativa Ação Reciclar no local de modo a tirar dúvidas da comunidade sobre o assunto, dias de coleta, etc. Essa ação objetivou sensibilizar a comunidade sobre a importância e as dificuldades do trabalho dos catadores cooperados no município de Poços de Caldas. 


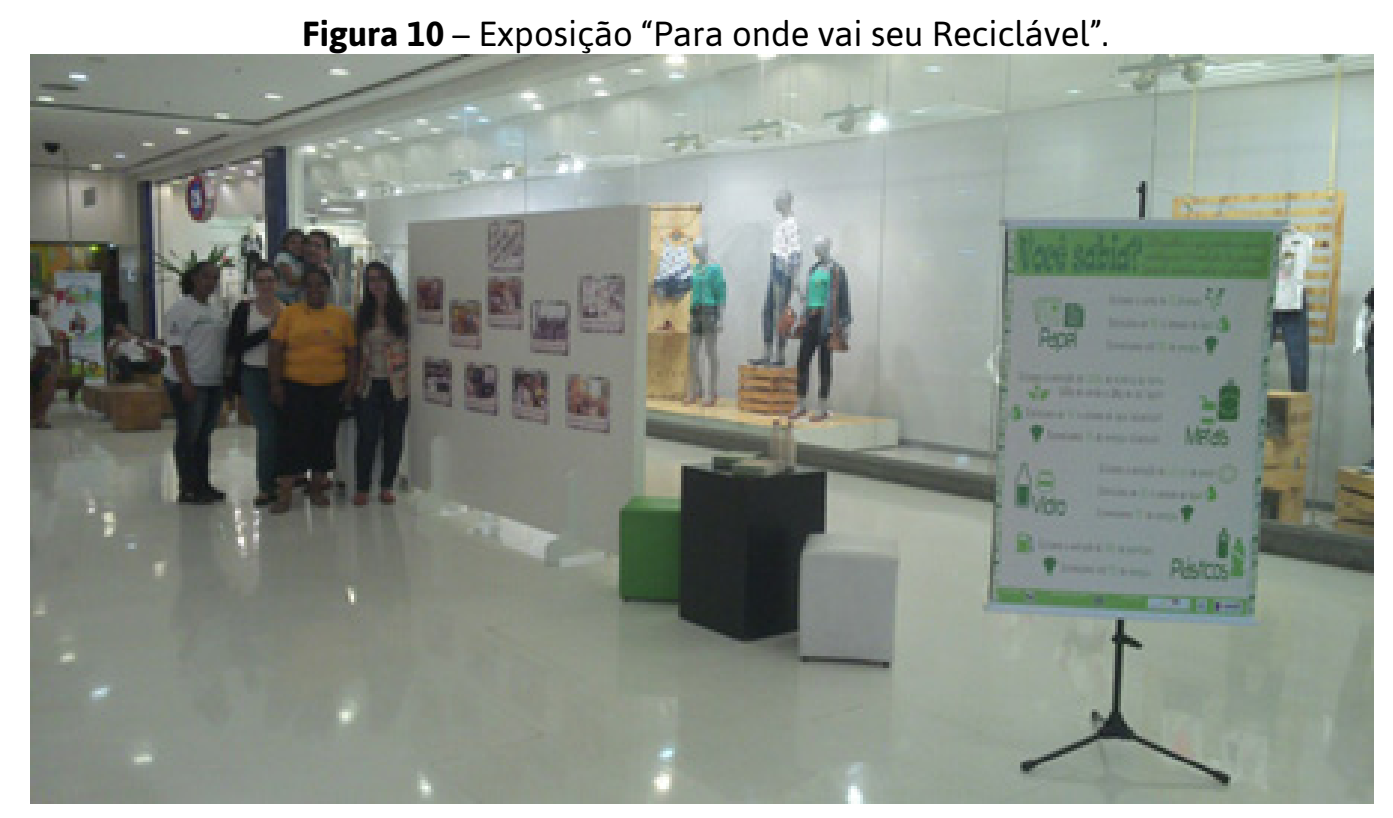

Fonte: autores

Na edição 2016 do Giro Sustentável, a atividade promovida pelo Recicla Unifal continuou na linha da educação ambiental. Desta vez, realizamos uma atividade precedente ao Giro sustentável de educação ambiental para a coleta seletiva promovendo bate-papo sobre o assunto em todas as salas de aula do Colégio Municipal Francisco Escobar (Fig. 11). Durante o Giro Sustentável, o Recicla UNIFAL, a APS, a Cooperativa Ação Reciclar e o Colégio Francisco Escobar (com apoio de professores e alunos) realizou uma campanha porta-a-porta de educação ambiental nos bairros nos arredores do colégio, coletando todo o material encontrado nas ruas, conversando com moradores, informando-os da disponibilidade do colégio como Ponto de Entrega de material reciclável (Fig. 12). Todo o material coletado foi destinado à Cooperativa Ação Reciclar.

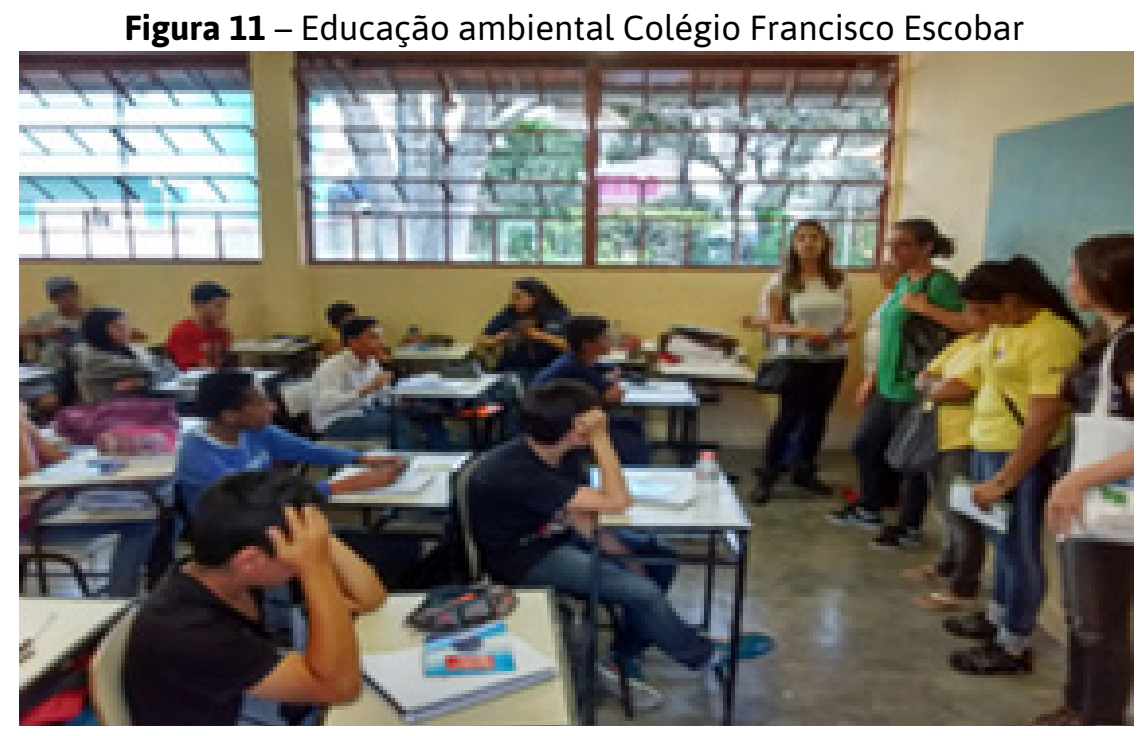

Fonte: autores 


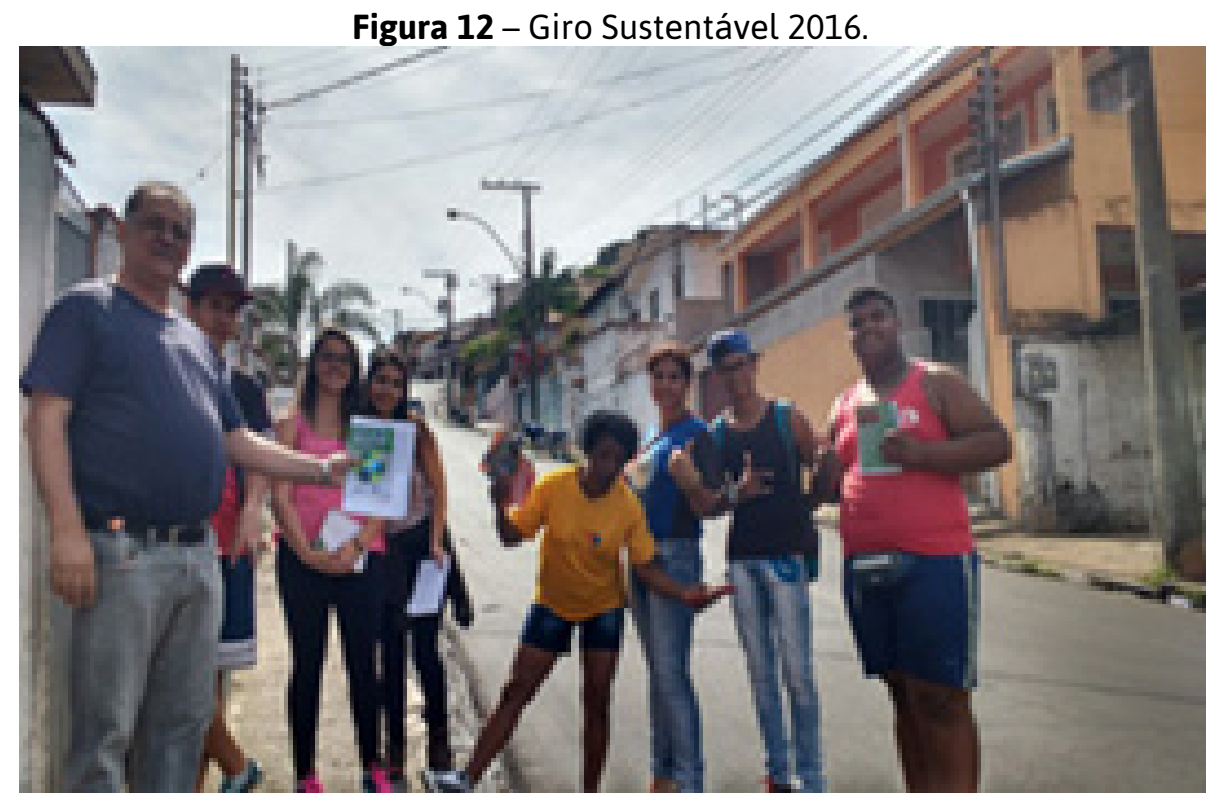

Fonte: autores

Entre os dias 18 a 20 de outubro de 2015, ocorreu o XXVI ENTMME (Encontro Nacional de Tratamento de Minérios e Metalurgia Extrativa) no Palace Cassino. O evento foi organizado pela UNIFAL e foi feito trabalho de divulgação sobre a coleta seletiva. A equipe Recicla UNIFAL conseguiu apoio da empresa M\&G Fibras Brasil para colocação de catorze coletores de papel pelo evento. Uma pessoa da cooperativa permaneceu no local durante o evento para efetuar a coleta e separação dos materiais.

Em 2016, o Recicla UNIFAL lançou a ação “Complementando o Recicla”. A ação propunha que os estudantes promovessem a coleta seletiva em seus condomínios, nas ruas da casa em que moram, a fim de coletar e armazenar o material coletado e, atingido um volume mínimo de 100L (estipulado pela cooperativa Ação Reciclar), contatar a cooperativa para a retirada do material. Aos estudantes, era solicitado o registro fotográfico da entrega do material a fim de reverter sua ação social em horas de atividades complementares. Essa ação foi mais uma forma que o Recicla Unifal encontrou que valorizar o trabalho da cooperativa. Na figura 13, pode-se ver a realização da entrega de material coletado por estudantes.

Dentre as atividades que foram mantidas pelo Recicla Unifal está a participação do na coleta seletiva de festas universitárias. A figura 14 ilustra o trabalho de coleta seletiva na festa "Vem Cá Morra IX".

Uma das ações externas mais significativas do Recicla Unifal foi o projeto piloto de implantação de PEV no bairro Campos Elísios, em junho de 2017. Esse projeto tem a participação da cooperativa Ação Reciclar e conta com o apoio da Prefeitura Municipal, principalmente da Coordenadoria da Zeladoria da Zona 
Oeste.

Figura 13 - Complementando o Recicla.

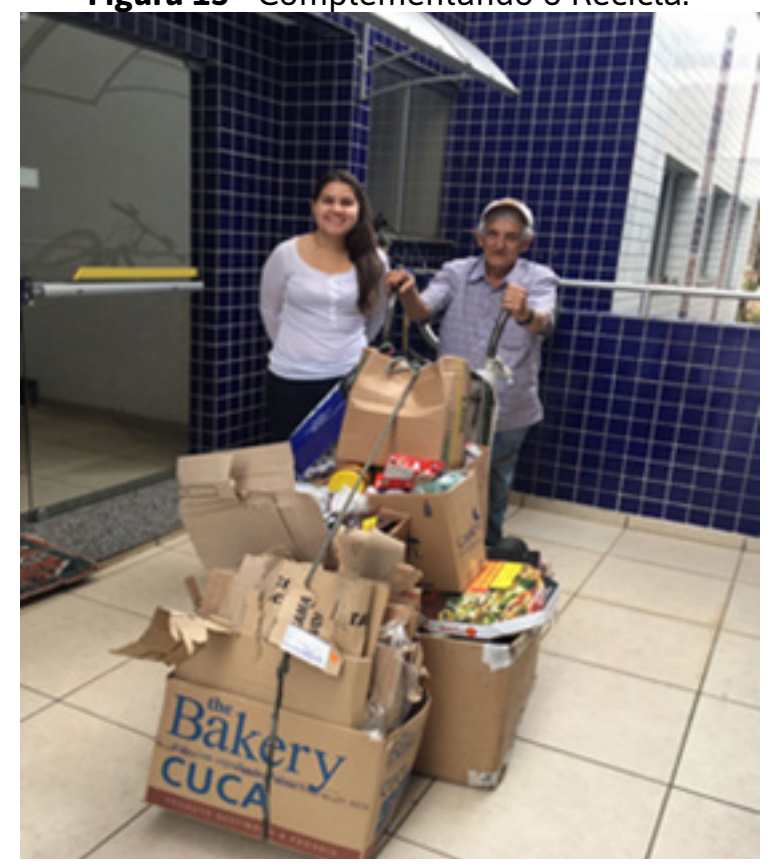

Fonte: autores

Figura 14 - Coleta seletiva em festas universitárias.

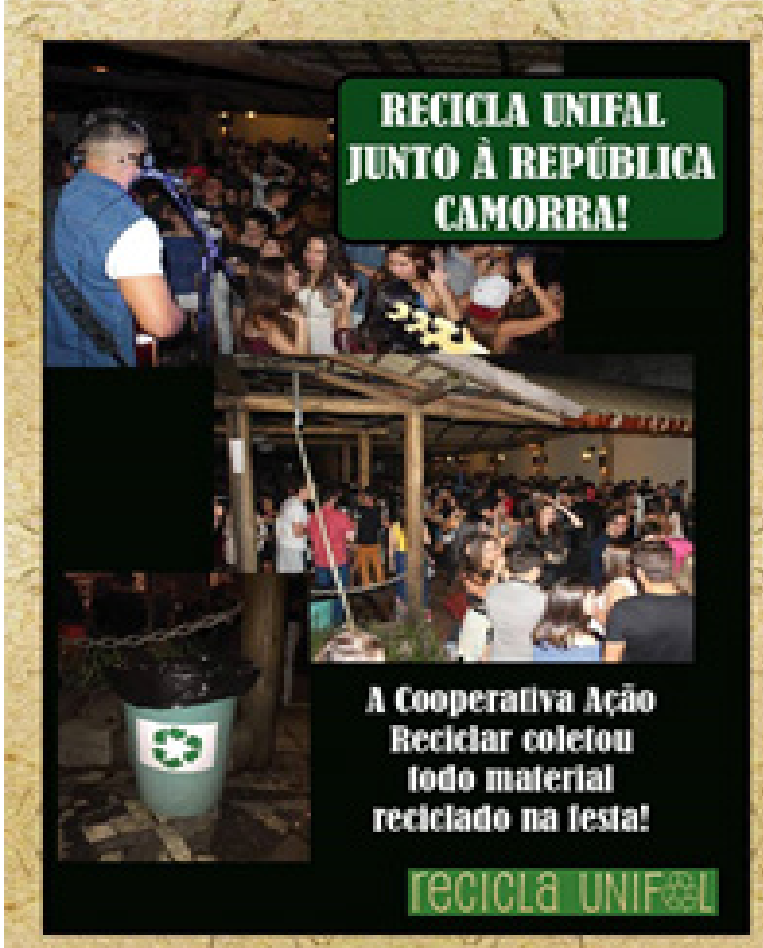

Fonte: autores 
As etapas do projeto de implantação do PEV foram as seguintes: 1) Escolha do bairro; 2) Levantamento dos dados da coleta seletiva no bairro; 3) Projeto e construção do PEV; 4) Campanha pré-instalação; 5) Instalação do PEV; 6) Campanha pós-instalação; 7) Levantamento de dados da coleta no PEV; 8) Análises de resultado.

Primeiramente, conjuntamente com a Cooperativa Ação Reciclar, escolheu-se o bairro Campos Elíseos para execução do projeto por ser um bairro pequeno, que não consiste em trajeto para outros locais da cidade (ou seja, há poucos frequentadores que não são moradores), e que está próximo da Cooperativa.

A segunda etapa do projeto consistiu em acompanhar a realização da coleta seletiva porta a porta nas sete ruas do bairro entre 11 de novembro de 2016 e 9 de dezembro de 2016. O tempo médio de coleta no bairro foi de cinquenta minutos. O peso total coletado em cada uma das amostras foi de: $182,5 \mathrm{~kg}$, $145,0 \mathrm{~kg}, 163,0 \mathrm{~kg}, 228,5 \mathrm{~kg}$. Vale ressaltar aqui que, como esperado, entre o final de novembro e início de dezembro, houve um aumento na quantidade de material coletado - conjectura-se que isso se deve ao aumento do consumo com o recebimento do $13^{\circ}$ salário e do Natal.

Esse levantamento permitiu-nos concluir que um único PEV não atenderia a demanda de todo o bairro. Assim, definiu-se que o PEV atenderia apenas duas ruas do bairro. Escolheram-se as ruas Antônio de Castro Souza e Hélio Brandão Dias. A área pública de recreação localizada nesta última rua foi definida como local de instalação do PEV.

Em conjunto com a cooperativa Ação Reciclar, definiu-se que o PEV deveria ser resistente a ataques de vandalismo e dificultar o furto de material. Com essas premissas, os alunos do Recicla Unifal e os técnicos da UNIFAL-MG fizeram o projeto do PEV que pode ser visto na figura 15. A estrutura do PEV é toda feita em metalom e seu revestimento em chapa de aço galvanizado; para dificultar o furto de material, a portinhola para descarte de material foi construída na parte frontal e superior do PEV.

Em maio de 2017, um mês antes da instalação do PEV iniciou-se a campanha de divulgação orientando os moradores das duas ruas relatadas da mudança de logística na coleta seletiva nessas ruas, que passariam a ser atendidos exclusivamente pelo PEV. Uma vez por semana a equipe do Recicla Unifal entregou os panfletos informativos em cada uma das casas das duas ruas em questão.

Após aprovação da prefeitura municipal, através da Secretaria de Serviços Públicos, no dia 8 de junho de 2017 o PEV foi instalado. A Coordenadoria da Zona 
Oeste orientou o serviço de coleta porta a porta para que não mais realizasse a coleta nessas duas ruas. A coleta no PEV ficou de responsabilidade da Cooperativa.

As primeiras coletas no PEV foram realizadas nos dias 13, 20 e 27 de junho de 2017, e no dia 4 de julho de 2017 - a campanha informativa da alteração de logística de coleta foi mantida durante essas semanas. Nessas primeiras coletas notou-se uma considerável quantidade de material não reciclável no PEV. Então, uma segunda campanha foi realizada - esta campanha teve o intuito não apenas de informar sobre a mudança na logística de coleta, mas também de orientar os moradores sobre o tipo de material que poderia ser descartado no PEV. A Tabela 1 mostra a quantidade, em quilogramas, de material reciclável coletado nas duas ruas atendidas pelo PEV antes da instalação do mesmo, nas quatro semanas seguintes e após a segunda campanha orientadora.

Tabela 1 - Dados em kg de materiais reciclados coletados

\begin{tabular}{|c|c|c|}
\hline${\text { Antes da } \mathbf{1}^{\text {a }} \text { campanha* }}^{*}$ & Após $\mathbf{1}$ mês & Após a $\mathbf{2}^{\text {a campanha }}$ \\
\hline 52,1 & 47,8 & 67,2 \\
\hline 46,6 & 26,4 & 47,0 \\
\hline 65,3 & 48,0 & 36,0 \\
\hline 41,4 & 28,0 & 36,0 \\
\hline
\end{tabular}

*Valores médios gerados a partir dos dados de coleta porta a porta no bairro.

Figura 15 - PEV instalado no bairro Campos Elísios.

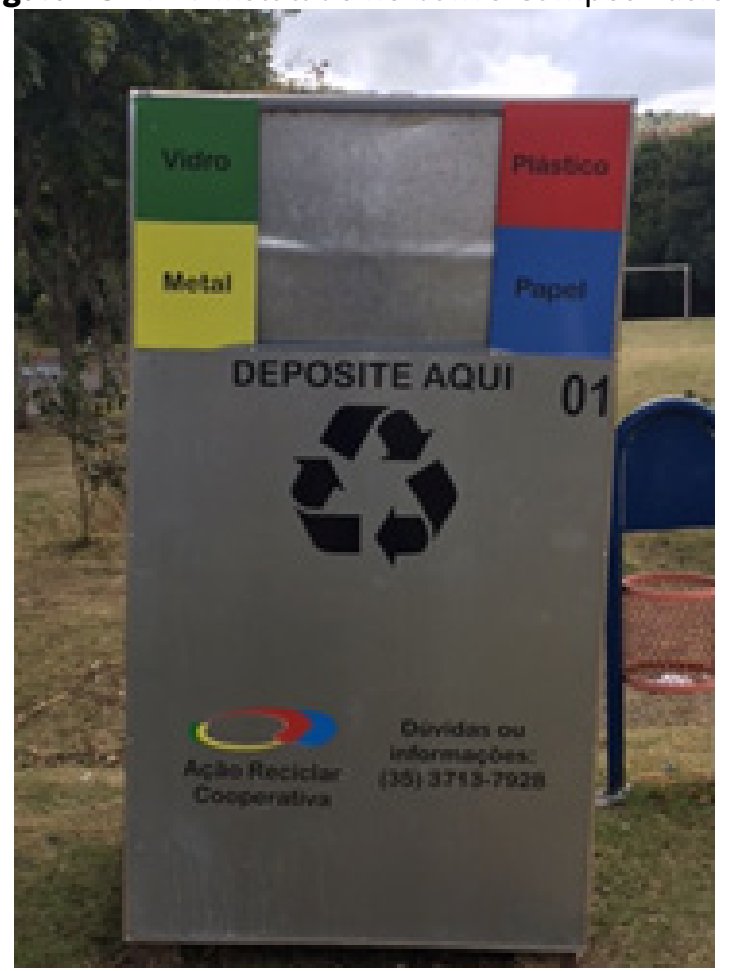

Fonte: autores 
Um Teste-t com um erro de $5 \%$ foi utilizado para avaliar se há diferença significativa entre as médias de duas amostras. A partir do teste podemos concluir que após a implantação do PEV, as médias da quantidade de material coletado nessas ruas mantiveram-se constantes. Assim, verificou-se a viabilidade do uso de PEV em bairros.

Destacamos que a coleta no PEV é feita por um catador autônomo parceiro da Cooperativa Ação Reciclar.

\section{DISCUSSÕES}

Como resultado direto das ações do Recicla Unifal, a retirada de material feita pela cooperativa, que era feita quinzenalmente no campus, passou a ser feita semanalmente devido ao aumento da quantidade de material selecionado. Além disso, a cooperativa Ação Reciclar relatou que houve melhora da seleção de material durante a execução do projeto.

A coleta seletiva efetiva e o trabalho de educação ambiental voltado à coleta seletiva levam à melhoria na seleção ao longo dos anos, no entanto, os monitoramentos revelaram que a separação não é total, ou seja, há descarte de material não reciclável em lixeiras destinadas a material reciclável. Esse fato mostra que o trabalho de educação ambiental deve ser uma ação continuada.

O "República Amiga Recicla Unifal” e o trabalho de coleta seletiva em eventos e festas universitárias tem se mostrado ação muito efetiva de acordo com a Cooperativa Ação Reciclar, que faz a coleta nas moradias estudantis, eventos e festas.

Um ponto a ser melhorado é o acondicionamento do material reciclável selecionado no campus. Principalmente com o contínuo aumento de material, o Ecoponto não tem sido suficiente para armazenamento do material até sua retirada. A construção de um abrigo é uma das próximas ações do projeto, dependendo apenas de recursos para ser executada.

Com relação às ações externas, o Recicla Unifal vem mantendo sua participação em eventos e campanhas de mobilização social promovidas pela APS e Cooperativa Ação Reciclar. Pretendemos, contudo, intensificar essas ações desenvolvendo um projeto de promoção de coleta seletiva em todas as escolas municipais de Poços de Caldas, a ação englobará tanto o trabalho de educação ambiental quanto de estruturação da escola para implantação da coleta seletiva. O ótimo resultado do projeto piloto de implantação de PEV em bairro é satisfatório, pois mostra que os moradores continuaram contribuindo com a coleta seletiva após a implantação do PEV, porém agora levam o material até o ponto de entrega para descarte. Além disso, pode-se considerar uma economia no tra- 
jeto do caminhão que até então fazia a coleta porta a porta. Diante dos resultados, espera-se ampliar o sistema para instalar mais PEV a fim de abranger todo o bairro e quiçá a cidade de Poços de Caldas.

\section{AGRADECIMENTOS}

Agradecemos todo apoio da UNIFAL-MG, Cooperativa Ação Reciclar, Prefeitura Municipal de Poços de Caldas.

\section{REFERÊNCIAS}

ASSOCIAÇÃO BRASILEIRA DE EMPRESAS DE LIMPEZA PÚBLICA E RESÍDUOS ESPECIAIS (ABRELPE). Panorama dos resíduos sólidos no Brasil 2010. [S. l. : s. n.], 2010.

BASSANI, Patrícia. Dornelas.Caracterização de resíduos sólidos de coleta seletiva em condomínios residenciais: estudo de caso em Vitória - ES. 2011. 187 f. Dissertação (Mestrado em Engenharia Ambiental) - Programa de Pós-Graduação em Engenharia Ambiental.Universidade Federal do Espírito Santo. Vitória, 2011.

BRASIL. Decreto ${ }^{\circ} 5.940$, de 25 de outubro de 2006. Separação dos resíduos recicláveis descartados pelos órgãos e entidades da administração pública federal direta e indireta, na fonte geradora, e a sua destinação às associações e cooperativas dos catadores de materiais recicláveis.

BRASIL. Lei n 12.305, 2010. Política Nacional de Resíduos Sólidos.

BRINGHENTI, Jaqueline. Coleta seletiva de resíduos sólidos: aspectos operacionaiseda participação da população. 2004. 234 f. Tese (Doutorado em Saúde Pública) - Faculdade de Saúde Pública. Universidade de São Paulo. São Paulo, 2004.

COMPROMISSO EMPRESARIAL PARA RECICLAGEM (CEMPRE). Pesquisa anual sobre a coleta seletiva. São Paulo: CEMPRE, 2010.

Radiografando a coleta seletiva. São Paulo: CEMPRE, 2012.

.Review2013. São Paulo: CEMPRE,2013.

.Guia da coleta seletiva de lixo. 2.ed. São Paulo: CEMPRE, 2014.

COMPROMISSO EMPRESARIAL PARA RECICLAGEM (CEMPRE). CEMPRE Review 2015. 2015. 
CRUSEIRO, F. A.; MARSON, I.; MILANI, P. H. Otimização de logística: nova etapa na coleta seletiva em Santo André.Disponível em: <https://slidex.tips/download/ otimizaao-de-logistica-nova-etapa-na-coleta-seletiva-em-santo-andre>. Acesso em: 7 fev. 2018.

FRÉSCA, F. R. C. Estudo da geração de resíduos sólidos domiciliares no município de São Carlos, SP, a partir da caracterização física. 2007. 133 f. Dissertação (Mestrado em Engenharia Ambiental) - Escola de Engenharia de São Carlos. Universidade de São Paulo. São Carlos, 2007.

FUZARO, J. A.; RIBEIRO, L. T.Coleta seletiva para prefeituras. 4.ed.São Paulo: SMA/CPLEA, 2005.

INSTITUTO BRASILEIRO DE GEOGRAFIA E ESTATÍSTICA (IBGE). Pesquisa nacional de saneamento básico - 2008: gestão municipal do saneamento básico. [Brasília: IBGE], 2008.

.Perfil dos municípios brasileiros 2011. [Brasília: IBGE], 2011.

Perfil dos municípios brasileiros 2015.[Brasília: IBGE], 2015.

MARCHEZETTI, A. L. Avaliação de alternativas tecnológicas para o tratamento de resíduos sólidos domiciliares pela aplicação do método AHP: estudo de caso da região metropolitana de Curitiba. 2009. Dissertação (Mestrado) - Programa de Pós-Graduação em Engenharia de Recursos Hídricos e Ambiental. Universidade Federal do Paraná. Curitiba, 2009.

MINAS GERAIS.Lei n. ${ }^{\circ} 18719$, de 13 de janeiro de 2010. Política estadual de resíduossólidos. Belo Horizonte, 2010.

POÇOS DE CALDAS. Lein. ${ }^{\circ}$ 8.316, de 13 de outubro de 2006, Decreto n. 8853/07. Política de gestão deresíduos sólidos reutilizáveis e incentivos à coleta seletiva de lixo no município de Poços de Caldas. Poços de Caldas, 2006.

\section{REDAÇÃO ECOD. Política Nacional de Resíduos Sólidos é sancionada em} Brasília. [S. n. t.].

RIBEIRO, T.; LIMA, S.Coleta seletiva de lixo domiciliar: estudo de casos. Caminhos de Geografia, v. 1 n. 2, p. 50-69, 2000.

SOUZA et al. Coleta seletiva nas universidades: um estudo do Campus de Poços de Caldas da Universidade Federal de Alfenas (UNIFAL). Projeto Multidisciplinar V. Bacharelado Interdisciplinar em Ciência e Tecnologia. Universidade Federal de Alfenas, 2014. 
ZANLUCA, J. C.Como funcionam as cooperativas? [S. l.: s. n.], 2012.

Data de recebimento: 02 de março de 2018.

Data de aceite para publicação: 07 de maio de 2018. 